\title{
Молекулярно-филогенетические исследования Cystopteridaceae Южной Сибири
}

\section{Molecular-phylogenetic study of the Cystopteridaceae family in South Siberia}

\author{
Гуреева И. И., Улько Д. О., Романец Р. С., Кузнецов А. А. \\ Gureyeva I. I., Ulko D. O., Romanets R. S., Kuznetsov A. A. \\ Томский государственный университет, г. Томск, Россия.E-mail: gureyeva@yandex.ru, ulko.den@gmail.com, \\ romankelevra@tambo.ru,ys.tsu@mail.ru \\ Tomsk State University, Tomsk, Russia
}

\begin{abstract}
Peферат. Приводятся результаты молекулярно-филогенетических исследований, основанных на секвенировании локуса $m a t K$ хлоропластной ДНК представителей семейства Cystopteridaceae, обитающих на территории Южной Сибири. Полученные результаты подтвердили мнение о таксономической сложности Cystopteris и Gymnocarpium, особенно видов типового подрода Cystopteris и видов Gymnocarpium с железистым опушением вай. В роде Gymnocarpium разделились виды с железистым опушением и без него, как сестринские отделились алтайский образец G. robertianum и памирский $G$. fedtschenkoanum. Не удалось разделить виды с железистым опушением (G. continentale, G. jessoense и G. tenuipes) и виды типового подрода Cystopteris, описанные с территории Сибири - Cystopteris altajensis и C. gureeva c C. fragilis и C. dickieana. Это может быть свидетельством современного видообразования в обоих родах путем гибридизации в сочетании с полиплоидией и образования большого числа аллополиплоидных таксонов, которые невозможно разделить по локусу matK хлоропластной ДНК. Анализ подтвердил обособленность Cystopteris montana от остальных видов Cystopteris и C. sudetica от видов типового подрода, что свидетельствует в пользу выделения монотипного рода Rhizomatopteris включающего Rh. montana, и позволяет признать выделение секции Khokhrjakovia (с C. sudetica) в пределах рода Cystopteris.
\end{abstract}

Ключевые слова. Систематика, филогения, хлоропластная ДНК, Cystopteridaceae, Cystopteris, Gymnocarpium, matK.

Summary. The results of molecular-phylogenetic study based on sequencing of the maturase $\mathrm{K}$ ( $m a t K$ ) locus of chloroplast DNA of the Cystopteridaceae family occurred in South Siberia are given. These results confirmed the view of the taxonomic complexity of Cystopteris and Gymnocarpium, especially of the subgenus Cystopteris and Gymnocarpium species with glandular pubescent fronds. Within the genus Gymnocarpium, the species with glandular pubescent fronds separated from the species with glabrous fronds. Gymnocarpium robertianum from the Altai and G. fedtschenkoanum from Pamir are separated as the sister to other species with glandular fronds. It is failed to separate species with glandular pubescent fronds from each other. The Cystopteris species described from Siberia - C. altajensis and C. gureeva - failed to separate with $C$. fragilis and $C$. dickieana. This may be evidence of their modern speciation by hybridization in combination with polyploidy and the formation of a large number of allopolyploid taxa that cannot be separated by the matK locus of the chloroplast DNA. Nevertheless, this analysis once again confirmed the isolation of Cystopteris montana from other Cystopteris species, and $C$. sudetica from other members of subgenus Cystopteris. This allows to recognize both the monotypic genus Rhizomatopteris (including Rh. montana) and the section Khokhrjakovia (including Cystopteris sudetica) within the genus Cystopteris.

Key words. Cystopteridaceae, Cystopteris, Gymnocarpium, chloroplast DNA, matK, systematics, phylogeny.

\section{Введение}

Семейство Cystopteridaceae (Payer) Schmakov было выделено в качестве самостоятельного А. И. Шмаковым (2001), затем признано М. J. M. Christenhusz с соавторами (2011). В дальнейшем самостоятельность семейства подтверждена молекулярно-филогенетическими исследованиями трех локусов хлоропластной ДНК (Rothfels et al., 2012, 2013). А. И. Шмаков (2001) принимал это семейство в объеме 3 родов: Cystopteris Bernh., Pseudocystopteris Ching и Gymnocarpium Newman; C. Rothfels c co- 
авторами (2013) считают, что в мировой флоре семейство представлено четырьмя родами Acystopteris Nakai, Cystoathyrium Ching, Gymnocarpium и Cystopteris; последний является наиболее крупным родом семейства - 27 видов, род Gymnicarpium включает 7 видов (Rothfels, 2013). В опубликованном недавно обзоре рода Cystopteris мировой флоры А. И. Шмаков с соавторами (Shmakov et al., 2018) признают 32 вида и 5 гибридов, распространенных в Северном и Южном Полушариях. С территории Сибири описано 3 вида - Gymnocarpium continentale (Petrov) Pojark. (Петров, 1930), Cystopteris altajensis Gureeva (Гуреева, 1985) и C. gureevae Stepanov (Степанов, 2015); 2 вида, описанных из Казахстана - Gymnоcarpium tenuipes Pojark. ex Shmakov (Шмаков, 1995) и Cystopteris almaatensis Kotukh. (Котухов, 1966), недавно приведены для Алтая (Шмаков, 1995; Гуреева и др., 2015). В целом, по современным взглядам, на территории Сибири семейство Cуstopteridaceae представлено двумя родами - Gymпосаrpium (6 видов) и Cystopteris (7 видов). Из всех видов наиболее постоянными признаками обладают Cystopteris sudetica A. Braun et Milde и C. montana (Lam.) Bernh. ex Desv., границы между остальными видами внутри родов не вполне ясны. О сложности внутриродовой систематики Cystopteris и Gymnocarpium высказывались многие исследователи. Как заметил В. Н. Сипливинский (1973: 353), «трудности распознавания сибирских Gymпосагріuт обратно пропорциональны их видовому разнообразию». Мнение в отношении Cystopteris сводится к тому, что Cystopteris fragilis-комплекс представляет, возможно, самую серьезную проблему биосистематики среди папоротников ("perhaps the most formidable biosystematics problem in the ferns") (Lovis, 1978: 356).

Сибирские представители семейства Суstopteridaceae до настоящего времени не были объектами молекулярно-филогенетических исследований. C. Rothfels с соавторами $(2013,2014)$, не имея материалов с территории России, не включили их в свое исследование. Поэтому целью настоящего исследования был молекулярно-филогенетический анализ родов Gymnocarpium и Cystopteris на основе секвенирования региона matK хлоропластной ДНК.

\section{Материалы и методы}

Для выделения ДНК использованы образцы, собранные на Западном Саяне (2015 г.) и Кузнецком Алатау (2016 г.), высушенные в силикагеле, в некоторых случаях - гербарные образцы видов обоих родов, хранящиеся в Гербарии им. П. Н. Крылова Томского государственного университета (ТК, Томск), ваучерные образцы хранятся в ТК. В анализ включен также памирский эндемик Gymnосагpium fedtschenkoanum Pojark., собранный и присланный Марчином Нобисом (KRA, Польша). ДНК выделяли по протоколу производителя наборов для выделения ДНК (Барнаул) или стандартным СТАВ методом (Rogers, Bendich, 1989). Качество и количество ДНК проверяли на спектрофотометре «Implen P330». Секвенирование региона matK хлоропластной ДНК проводилось с использованием двух пар праймеров AJmatKf1+AJmatKr3B и AJmatKf3+AJmatKr1 (Rothfels et al., 2013). ДНК всех образцов подготовлена к секвенированию в лаборатории структурного и молекулярного анализа растений ТГУ, секвенирование проводилось в ООО «Синтол» (Москва). Всего получено 39 нуклеотидных последовательностей 7 видов Cystopteris и 5 видов Gymnocarpium, включая 2 образца обоих родов с неясным определением. Полученные данные о последовательностях исследуемого региона выравнивались с применением алгоритма MUSCULE, филограммы построены методами Maximum Likelihood (ML) и MrBayes: ML согласно Tamura-Nei модели в пакете программ для обработки молекулярных данных MEGA X (Molecular Evolutionary Genetics Analysis) (Tamura, Nei, 1993; Kumar et al., 2015); байесовский анализ осуществлён в программе MrBayes 3.2.6 с учётом наилучшей модели нуклеотидных замен, протестированной в jModelTest 2.1.10. Филограмма построена после генерирования 600000 поколений деревьев, из полученных деревьев первые 25 \% отбрасываются.

\section{Результаты и обсуждение}

Клады и ветви в филограммах, полученных методами Maximum Likelihood и MrBayes почти совпадают, поэтому здесь приведена более ясная филограмма по MrBayes (рис. 1). В филограмме семейство Cystopteridaceae включает 2 суперклады, соответствующие родам Gymnocarpium и Cystopteris. В суперкладе, соответствующей роду Cystopteris, как сестринский со 100\%-ной апостериорной вероятностью от остальной части рода отделяется C. montana (三Rhizomatopteris montana (Lam.) A. P. 
Khokhr.). В остальной части рода с той же вероятностью от остальных видов Cystopteris отделяется ветвь $C$. sudetica. Такое положение $C$. montana и C. sudetica, говорит о том, что последний генетически ближе к остальным видам Cystopteris, чем к C. montana, с которым он объединялся в один надвидовой таксон - секцию Emarginatae Blasdell R. F. Blasdell'ом (1963) и в один подрод Emarginatae (Blasdell) Shmakov, но в разные секции - Emarginatae и Khokhrjakovia (Tzvel.) Shmakov А. И. Шмаковым с соавторами (2018). Как показано нами ранее (Гуреева, 2001; Gureyeva, Kuznetsov, 2015; Гуреева и др., 2018), C. montana и C. sudetica имеют больше различий, чем сходства: их длинные плетевидные ризомы отличаются разным способом ветвления и нарастания - филлогенное ветвление с моноподиальным нарастанием у C. montana и акрогенное ветвление с дихотомическим нарастанием у C. sudetica, на базальном пере наибольшую длину у первого имеет базальное базископическое перышко, у второго следующее за ним или третье от основания, скульптура периспория у первого образуется ширококоническими полыми сетчатыми структурами, у второго периспорий крупношиповатый. Подобная же топология C. montana и C. sudetica отмечается и в филограммах C. Rothfels с соавторами $(2013,2014)$. Taкие результаты не позволяют рассматривать C. sudetica и C. montana в составе одной секции (Blasdell, 1963), одного подрода (Шмаков, 2001, 2018) или рода (Хохряков, 1985), поскольку в этом случае надвидовой таксон будет парафилетическим. Опираясь не только на генетические, но и на хорошо выраженные фенетические различия, мы считаем возможным рассматривать C. montana в составе монотипного самостоятельного рода Rhizomatopteris A. Р. Khokhr., тем более, что именно этот вид был избран А.П. Хохряковым (1985) типовым видом описанного им рода. В таком понимании род Rhizomatopteris более родствен роду Cystopteris, чем роду Gymnocarpium. Cystopteris sudetica возможно оставить в секции Khokhrjakovia (Tzvel.) Shmakov, описанной Н.Н. Цвелевым (2005) в пределах рода Rhizomatopteris, но переведенной А.И. Шмаковым (2018) в род Cystopteris.

Основное число видов Cystopteris принадлежит оставшейся кладе, которую C. Rothfels c coaвторами (2013) называют C. fragilis-комплекс; формально эти виды принадлежат к типовому подроду (sensu Шмаков, 2001, 2018). Клада разделяется со 100 \%-ной апостериорной вероятностью с C. sudetica-кладой, и свою очередь со 100 \%-ной апостериорной вероятностью разделяется на 2 неразрешенные субклады и ветвь, включающую Cystopteris altajensis. В обеих субкладах одни и те же таксоны встречаются в разных ветвях или характеризуются неясной топологией. Cystopteris altajensis - гексаплоид ( $n=126)$ с шиповатыми спорами (Gureyeva, Kuznetsov, 2015; Gureyeva et al., 2017) и C. gureevae предполагаемый гексаплоид с шиповатыми спорами (Улько и др., 2017) в основном характеризуются неясной топологией, и лишь в одном случае $C$. gureevae входит в конечную ветвь, в которой объединяется с C. almaatensis из Монголии (предполагаемый гексаплоид со складчатыми спорами) (Gureyeva, Kuznetsov, 2015; Улько и др., 2017). Образец с неясным определением из Кузнецкого Алатау (Республика Хакасия, окр. пос. Сыя) объединился с C. fragilis (L.) Bernh. также из Кузнецкого Алатау (Республика Хакасия, окр. пос. Ефремкино). Этот таксон с неясным определением был обнаружен еще в 1982 г., от C. fragilis он отличается более крупными размерами, яйцевидной в общем очертании пластинкой вайи, образует выполненные споры, является гексаплоидом $(n=126)$, возможно будет описан в качестве нового подвида или вида. Вероятно, все виды C. fragilis-комплекса являются результатом аллополиплоидии, поэтому с помощью использованного хлоропластного локуса не разделяются.

В суперкладе Gymnocarpium хорошо разделились (апостериорная вероятность 100 \%) клады, включающие G. dryopteris (L.) Newman с нежелезистыми вайями и все виды с железистыми вайями. C видами с нежелезистыми вайями объединился образец с неясным определением (Gymnocarpium sp.), имеющий вайи, сходные с G. dryopteris, но с рассеянным железистым опушением. Такое его положение в филограмме, вероятно, связано с его гибридным присхождением от G. dryopteris и одного из видов с железистым опушением, скорее всего - G. continentale. В кладе, включающей виды с железистыми вайями, последовательно отделились алтайский образец G. robertianum (Hoffm.) Newman, затем памирский G. fedtschenkoanum. Такое же положение G. robertianum как сестринского ко всем остальным видам с железистым опушением зафиксировано и в филограмме, полученной C. Rothfels c coaвторами (2013). G. fedtschenkoanum находится в положении сестринского к комплексу, включающему G. jessoense (Koidz.) Koidz., G. continentale и G. tenuipes. Внутри этой клады виды имеют неясное положение, что требует исследований с использованием других локусов ДНК. 
«Проблемы ботаники Южной Сибири и Монголии» - XVIII Международная научно-практическая конференция

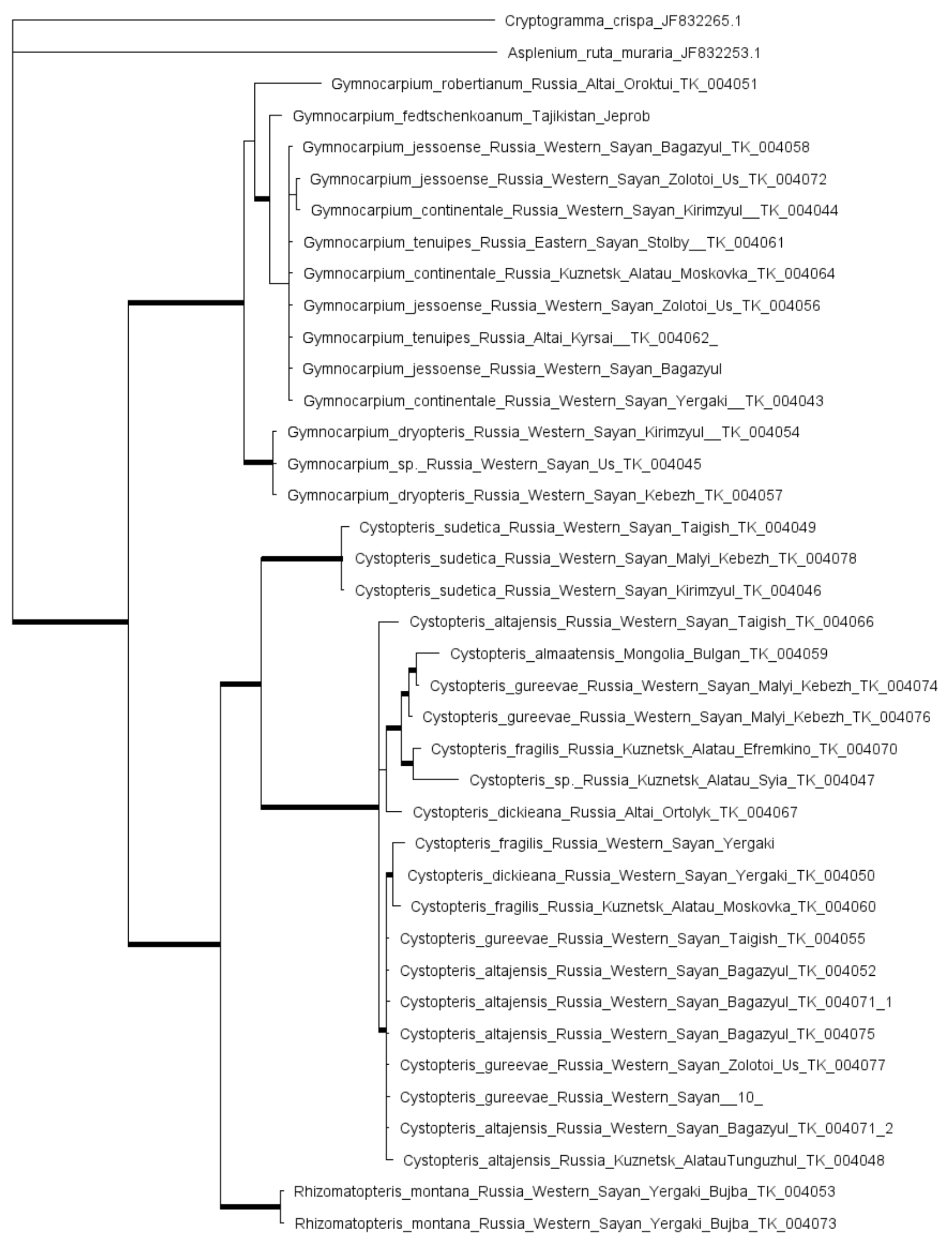

0.04

Рис. 1. Филограмма семейства Cystopteridaceae по локусу $m a t K$ хлоропластной ДНК, построенная методом MrBayes по образцам из Южной Сибири. Утолщенными линиями показаны ветви с апостериорной вероятностью $97-100 \%$. 


\section{Заключение}

Анализ встречающихся в Южной Сибири представителей семейства Сystopteridaceae, проведенный на основе секвенирования локуса $m a t K$ хлоропластной ДНК подтверждает, что мнение о таксономической сложности Cystopteris и Gymnocarpium вполне оправдано, особенно для видов типового подрода Cystopteris и видов Gymnocarpium с железистым опушением. На основе анализа matK не удалось определить топологию Cystopteris altajensis, C. gureeva и C. almaatensis по отношению к давно приводившимся для территории Сибири C. fragilis и $C$. dickieana R. Sim, не удалось разделить виды с железистым опушением Gymnocarpium continentale, G. jessoense u G. tenuipes. Это может быть свидетельством их современного видообразования путем гибридизации в сочетании с полиплоидией с образованием большого числа аллополиплоидных таксонов, которые невозможно разделить по использованному локусу. Анализ подтвердил обособленность C. montana от остальных видов Cystopteris, что свидетельствует в пользу выделения монотипного рода Rhizomatopteris, включающего Rh. montana, и позволяет признать выделение секции Khokhrjakovia (с C. sudetica) в пределах рода Cystopteris.

Благодарности. Работа выполнена при поддержке РФФИ (проекты №№ 18-34-00781 мол_a, 16 04-00513 А). Авторы благодарны д-ру биол. наук Н. В. Степанову (Сибирский федеральный университет) и канд. биол. наук С. П. Гурееву (Томский государственный университет) за помощь в сопровождении экспедиционного отряда на Западном Саяне (2015 г.) и Кузнецком Алатау (2016 г.).

\section{Appendix}

Studied specimens: Cystopteris almaatensis: Mongolia, Bulgan (TK-004059); Cystopteris altajensis: Russia, Western Sayan, Taigish (TK-004066); Russia, Western Sayan, Bagazyul (TK-004052, TK-004071, TK-004075); Russia, Kuznetsk Alatau,Tunguzhul (TK-004048); Cystopteris dickieana: Russia, Western Sayan, Yergaki (TK-004050); Russia, Altai, Ortolyk (TK-004067); Cystopteris fragilis: Russia, Kuznetsk Alatau, Efremkino (TK-004070), Western Sayan, Yergaki; Cystopteris gureevae: Russia, Western Sayan, Taigish (TK004055); Russia, Western Sayan, Malyi Kebezh (TK-004074; TK-004076); Russia, Western Sayan, Zolotoi Us (TK-004077); Cystopteris sudetica: Russia, Western Sayan, Taigish (TK-004049); Russia, Western Sayan, Kirimzyul (TK-004046); Russia, Western Sayan, Malyi Kebezh (TK-004078); Cystopteris sp.: Russia, Kuznetsk Alatau, Syia (TK-004047); Rhizomatopteris montana: Russia, Western Sayan, Yergaki, Bujba (TK004053, TK-004073) Russia, Western Sayan, Yergaki, Bujba; Gymnocarpium continentale: Russia, Western Sayan, Yergaki (TK-004043); Russia, Western Sayan, Kirimzyul (TK-004044); Russia, Kuznetsk Alatau, Moskovka (TK-004064); Gymnocarpium dryopteris: Russia, Western Sayan, Kebezh (TK-004057); Russia, Western Sayan, Kirimzyul (TK-004054); Gymnocarpium fedtschenkoanum: Tajikistan, Jeprob; Gymnocarpium jessoense: Russia, Western Sayan, Zolotoi Us (TK-004072, TK-004056); Russia, Western Sayan, Bagazyul (TK-004058); Russia, Western Sayan, Bagazyul (TK); Gymnocarpium robertianum: Russia, Altai, Oroktui (TK-004051); Gymnocarpium tenuipes: Russia, Altai, Kyrsai (TK-004062); Russia, Eastern Sayan, Stolby (TK-004061); Gymnocarpium sp.: Russia, Western Sayan, Us (TK-004045).

\section{ЛИТЕРАТУРА}

Гуреева И. И. Новый вид рода Cystopteris Bernh. из Южной Сибири // Систематические заметки по материалам Гербария им. П. Н. Крылова Томского государственного университета, 1985. - № 87. - С. 5-8.

Гуреева И. И. Равноспоровые папоротники Южной Сибири. Систематика, происхождение, биоморфология, популяционная биология. - Томск: Изд-во Том. ун-та, 2001. - 158 с.

Гуреева И. И., Кузнецов А. А., Улько Д. О. Находки Cystopteris almaatensis Kotukhov (Cystopteridaceae) на Алтае // Систематические заметки по материалам Гербария им. П. Н. Крылова Томского государственного университета, 2015. - № 112. - С. 62-65. DOI: 10.17223/20764103.112.7.

Гуреева И. И., Улько Д. О., Кузнецов А. А. Биоморфологические и морфометрические признаки спорофитов в систематике папоротников семейства Cystopteridaceae // Бюллетень Ботанического сада-института ДВО РАН, 2018. - Вып. 19. - С. 1-12. DOI: 10.17581/bbgi1901

Котухов Ю. А. Новый вид рода Cystopteris Bernh. из Юго-Восточного Казахстана // Ботанические материалы Гербария института ботаники АН КазССР. - Алма-Ата: Наука, 1966. - Вып. 4. - С. 27-30. 
Петров В. А. Флора Якутии. - Л.: Изд-во АН СССР, 1930. - Вып. 1. - 221 с.

Сипливинский В. Н. Заметки о байкальской флоре, 1 // Новости систематики высших растений. - Л.: Наука, 1973. - С. 345-365.

Степанов Н. В. О трех новых видах сосудистых растений из Западного Саяна // Систематические заметки по материалам Гербария им. П. Н. Крылова Томского государственного университета, 2015. - № 111. - С. 3-15.

Улько Д. О., Гуреева И. И., Шмаков А. И., Романец Р. С. Морфология спор видов подрода Cystopteris (Cystopteris Bernh., Cystopteridaceae) // Turczaninowia, 2017. - T. 20, № 2. - C. 5-15. doi: 10.14258/turczaninowia.20.2.1

Хохряков А. П. Дополнение (Описания новых растений) // Флора Магаданской области. - М.: Наука, 1985. C. 347-348.

Цвелев Н. Н. Краткий конспект сосудистых споровых растений Восточной Европы // Новости систематики высших растений. - Санкт-Петербург: Изд-во Бот. ин-та им. В.Л. Комарова, 2005. - Т. 37 - С. 7-32.

Шмаков А. И. Конспект папоротников Алтая, Тянь-Шаня и Семиречья // Флора и растительность Алтая, 1995. - T. 1. - C. 35-53.

Шмаков А. И. Конспект папоротников России // Turczaninowia, 2001. - Т. 4, № 1-2. - С. 36-72.

Blasdell R. F. A monographic study of the fern genus Cystopteris // Mem. Torrey Bot. Club., 1963. - Vol. 21. - P. 1-102.

Christenhusz M. J. M., Zhang X.-C., Schneider H. A linear sequence of extant families and genera of lycophytes and ferns // Phytotaxa, 2011. -Vol. 19. - P. 7-54.

Gureyeva I. I., Kuznetsov A. A. Spore morphology of the north Asian members of Cystopteridaceae // Grana, 2015. Vol. 54, № 3. - P. 213-235. DOI: 10.1080/00173134.2015.1048824.

Gureeva I. I. Mitrenina E. Yu., Ulko D. O. Cystopteridaceae. IAPT/IOPB chromosome data 26 // Taxon, 2017. - Vol. 66, № 6. - P. 1489-1490 [print version]; P. E9-E10 [online version]. DOI: https://doi.org/10.12705/666.30.

Kumar S., Stecher G., Li M., Knyaz C., Tamura K. MEGA X: Molecular Evolutionary Genetics Analysis across computing platforms // Molecular Biology and Evolution, 2018. - Vol. 35. - P. 1547-1549.

Lovis $\boldsymbol{J}$. Evolutionary patterns and processes in ferns // Advances in Botanical Research, 1978. - Vol. 4. - P. $229-415$.

Rogers S. O., Bendich A. J. Extraction of DNA from plant tissues // Plant Molecular Biollogy Manual, 1989. - P. 73-83.

Rothfels C. J., Sundue M. A., Kuo L.-Y., Larsson A., Kato M., Schuettpelz E., Pryer K. M. A revised family-level classification for eupolypod II ferns (Polypodiidae: Polypodiales) // Taxon, 2012. - Vol. 61, № 3. - P. $515-533$.

Rothfels C. J., Windham M. D., Pryer K. M. A plastid phylogeny of the cosmopolitan fern family Cystopteridaceae (Polypodiopsida) // Systematic Botany, 2013. - Vol. 38, № 2. - P. 295-306.

Rothfels C. J., Johnson A. K., Windham M. D., Pryer K. M. Low-copy nuclear data confirm rampant allopolyploidy in the Cystopteridaceae (Polypodiales) // Taxon, 2014. - Vol. 63, № 5. - P. 1026-1036.

Shmakov A. I., Batkin A. A., Vaganov A. V. Synopsis of the genus Cystopteris Bernh. (Cystopteridaceae) // Ukrainian Journal of Ecology, 2018. - Vol. 8, № 4. - P. 290-297.

Tamura K., Nei M. Estimation of the number of nucleotide substitutions in the control region of mitochondrial DNA in humans and chimpanzees // Molecular Biology and Evolution, 1993. - Vol. 10. - P. 512-526. 